J. Lake Sci. (湖泊科学) , $2007, \mathbf{1 9}(3): 269-274$

http:// www. jlakes. org. E-mail: jlakes@ niglas. ac.cn

(c) 2007 by Journal of Lake Sciences

\title{
结合高光谱数据反演吉林石头口门水库悬浮物含量和透明度”
}

\author{
徐京萍 ${ }^{1,2}$, 张 柏 $^{1}$, 荡 钰 $^{3}$, 宋开山 ${ }^{1}$, 段洪涛 ${ }^{1,2}$, 王宗明 ${ }^{1}$ \\ ( $1:$ 中国科学院东北地理与农业生态研究所,长春 130012) \\ (2: 中国科学院研究生院, 北京 100039$)$ \\ (3: 呼和浩特市环境保护局, 呼和浩特 010021 )
}

\begin{abstract}
摘 要: 水中悬浮物含量是评价水环境质量的一个重要参数, 它可影响水体透明度、混浊度、水色等光学性质, 决定太阳光 照在水下的分布和浮游植物对光照的利用,并最终影响水体的初级生产力. 本文利用长春市石头口门水库的高光谱实测 数据和水质采样分析数据,尝试通过一阶微分法建立悬浮物估测模型,再用估测结果反演透明度信息. 结果表明: 用 590 $\mathrm{nm}$ 处的一阶微分光谱值建立的悬浮物估测模型的决定系数 $R^{2}$ 和均方根误差 $(R M S E)$ 分别为 $0.76 、 9.09 \mathrm{mg} / \mathrm{L}$, 验证模型 的 $R^{2}$ 和 $R M S E$ 分别为 $0.79 、 7.15 \mathrm{mg} / \mathrm{L}$; 石头口门水库上游严重的水土流失导致透明度受悬浮物含量影响较大, 两者存在 明显的指数关系, 相关系数 $r$ 为 -0.80 , 用悬浮物含量建立的透明度估测模型的 $R^{2}$ 和 $R M S E$ 分别为 0.79 和 $0.12 \mathrm{~m}$, 验证 模型的 $R^{2}$ 和 $R M S E$ 分别为 $0.82 、 0.11 \mathrm{~m}$. 显著水平均为 $p<0.01$. 研究结果表明, 该方法用于石头口门水库悬浮物含量和 透明度的定量遥感结果较理想.
\end{abstract}

关键词: 石头口门水库;悬浮物; 透明度; 高光谱模型; 遥感

\section{Estimating total suspended sediments concentrations and transparency with hyper-spectral reflectance in Shitoukoumen Reservoir, Jilin Prvoince}

\author{
XU Jingping ${ }^{1,2}$, ZHANG Bai ${ }^{1}$, LIN Yu ${ }^{3}$, SONG Kaishan ${ }^{1}$, DUAN Hongtao ${ }^{1,2}$ \& WANG Zhongming ${ }^{1}$ \\ (1: Northeast Institute of Geography and Agricultural Ecology, CAS, Changchun 130012, P. R. China) \\ (2: Graduate School of CAS, Beijing 100039, P. R. China) \\ (3:Environmental Protection Bureau of Hohhot City, Hohhot 010021,P. R. China)
}

\begin{abstract}
Concentrations of total suspended sediments (TSS) and transparency ( SDD) are important indicators of water quality. In order to determine them of inland water using remote sensing, field hyperspectral data and water samples were collected in the Shitoukoumen Reservoir of Changchun on April 27 and June 28, 2006. The serious soil erosion upriver led to close exponential relationship between TSS concentrations and secchi disk transparency ( correlation coefficient was -0.80 ), which facilitated the estimation of secchi disk depth $(S D D)$ with TSS concentrations. It was found that the first-derivative model at $590 \mathrm{~nm}$ gave the best result to estimate TSS (determination coefficient $R^{2}$ was 0.76 and root mean square error $(R M S E)$ was $\left.9.09 \mathrm{mg} / \mathrm{L}\right)$. The estimate result could be used to calculate the $S D D\left(R^{2}\right.$ and $R M S E$ of the model were $0.79,0.12 \mathrm{~m}$ respectively at significant level $\left.P<0.01\right)$. Although the method presented here fits the data for Shitoukoumen Reservoir of Changchun, further analysis of reflectance in relation to water quality should be required from numerous geographic regions before universal equations could be established.
\end{abstract}

Keywords: Shitoukoumen Reservoir; total suspended sediments; secchi disk transparency; hyperspectral model; remote sensing

* 中国科学院知识创新工程重要方向项目 (KZCX3 - SW - 356)、中国科学院资源环境领域野外台站基金、国家自然 科学基金 (40401003,40371082)、中国科学院 “东北之春” 人才培养计划和中国科学院东北振兴科技行动计划重大 项目联合资助. 2006-08-07 收稿;2006-11-01 收修改稿. 徐京萍,女,1982 年生, 博士研究生; E-mail: xjingping @ gmail. com. 
石头口门水库是长春市主要水源地之一, 是该市工业、农业和人民群众生产、生活的重要保障. 然而多 年来, 由于滥砍滥伐、乱开荒、无计划采石、挖沙、开矿等原因使得水库上游部分地区水土流失严重, 大量的 农药、化肥、污水、泥沙流人库区内,造成水库水质污染严重, 威胁着广大人民群众的身体健康, 制约着城市 的发展. 因此保护好水源地关系到长春市经济发展和社会稳定,应是当务之急. 常规的水质检测手段费时 费力, 对水库总体的水质情况难以全面了解, 遥感技术作为一种区域性水环境调查和监测手段, 可以克服常 规方法的这些不足. 利用遥感技术监测水质的关键是建立主要水质参数与光谱特征之间的响应关系, 目前 由于物理方法的理论基础不够完善, 经验方法建模精度较低,使得半经验方法成为最常见的建模手段 ${ }^{[1]}$. 并且近年来, 高光谱技术发展迅速, 其纳米级的光谱分辨率可以获得目标物的诊断性光谱特性, 利用其建立 各种半经验模型可大大提高水质参数反演的精度 ${ }^{[2,3]}$.

对水体而言, 水的光谱特征主要是由水体本身的物质组成决定, 主要包括叶绿素、悬浮物质 (TSS)、黄 色物质等, 同时又受到各种水状态的影响. 其中, 针对石头口门水库, 上游严重的水土流失带来了大量的泥 沙, 使得水中悬浮物质的含量成为评价水环境质量的一个重要参数. 它可影响水体透明度、混浊度、水色等 光学性质, 决定太阳光照在水下的分布和浮游植物对光照的利用, 并最终影响水体的初级生产力 ${ }^{[4]}$. 目前, 国内外已有许多学者利用遥感手段对其进行监测, 并取得了较大进展 ${ }^{[5-10]}$. 由于透明度 $(S D D)$ 也是描述水 体光学性质和水体能见度的一个重要参数, 它能直观反映湖水清澈和混浊程度, 是衡量水质优劣、评价湖泊 富营养化的一个重要指标 ${ }^{[11]}$, 并且透明度与叶绿素 $\mathrm{a} 、$ 悬浮物等有密切的内在联系 ${ }^{[12]}$, 因此本文根据研究 区域的特点尝试先通过高光谱反射率反演水体悬浮物含量, 再由其反演透明度信息, 取得了较理想的结果. 该研究不仅为多途径提取透明度信息提供一种思路, 也为今后利用星载高光谱传感器进行大面积悬浮物含 量、透明度定量遥感奠定基础.

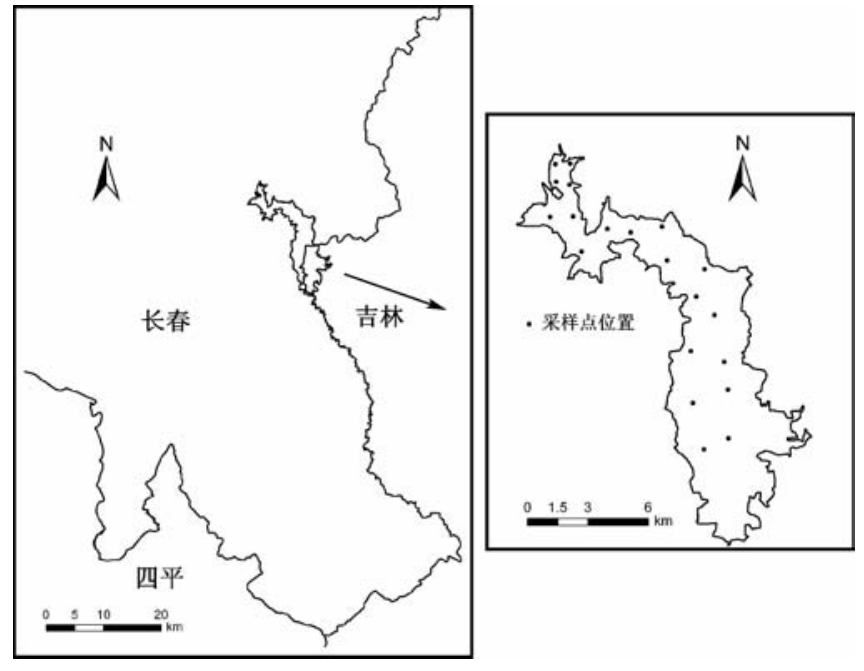

图 1 石头口门水库采样点分布图

Fig. 1 Distribution of sampling points

\section{1 试验方法与数据获取}

\section{1 研究区概况}

石头口门水库位于长春市东约 30 $\mathrm{km}$,坐落在饮马河的中游, 是一座以供水 为主兼有灌溉、旅游、防洪、发电和渔业 等功能的大型水库, 水库面积约 $73 \mathrm{~km}^{2}$, 控制流域面积 $4975.6 \mathrm{~km}^{2}$, 总库容 7.02 $\times 10^{8} \mathrm{~m}^{3}$. 目前每年向长春市供水 2.64 $\times 10^{8} \mathrm{~m}^{3}$, 向九台市供水 $1000 \times 10^{4} \mathrm{~m}^{3}$, 向长春国际机场供水 $300 \times 10^{4} \mathrm{~m}^{3}$, 基本 保证下游的农田灌溉, 是引松工程的重 要中转站, 是长春、九台等市的重要水源 地. 库区呈狭长型, 下游两侧为山区和 丘陵区, 山间支流两侧多有房屋和旱地. 库区上游有岔路河、双阳河两大支流, 库 区末端至忿路河、双阳河下游处地势平 坦, 土质肥沃, 良田集中, 人口稠密. 该

水库地处北温带大陆半湿润季风性气候区. 年均气温 $5.3^{\circ} \mathrm{C}$. 年降水量 $369.9-667.9 \mathrm{~mm}$, 降水多集中在 6 -9 月份, 占全年降水量的 $80 \%$. 年均蒸发量为 $1658.1 \mathrm{~mm}, 4-6$ 月份蒸发量最大, 占全年蒸发量的 $50 \%$, 常造成春旱和严重缺水的局面.

总体而言,石头口门水库水质情况较好,适宜做城市饮用水源. 但水库上游的水体流失使得大量泥沙 淤积, 抬高水库库底, 同时泥沙携带大量农药、化肥造成水库水质污染加剧, 其中铁、硝酸盐氮、苯并 (a) 芘、 矿物油和总磷含量超过《地面水环境质量标准》GHZB 1 - 1999 Ill 类标准, 水体已处于中等富营养化 状态 ${ }^{[13]}$. 


\section{2 数据获取及预处理}

分别于 2006 年 4 月 27 日和 6 月 28 日对石头口门水库代表点位进行水体的反射光谱测量, 同步测量水 体透明度和采集水样,并用 GPS 对采样点进行定位, 采样点位置分布见图 1. 光谱测量时间在 $10: 00-14$ : 00 , 天空基本晴朗无云, 水面平静. 所用仪器为美国 ASD 公司生产的 Fieldspec FSR VNIR ${ }^{\mathbb{E}}$ 野外光谱仪,可 在 $350-1050 \mathrm{~nm}$ 波长范围内进行连续测量, 采样间隔为 $1.4 \mathrm{~nm}$, 光谱分辨率 $3 \mathrm{~nm}$, 视场角 $25^{\circ}$. 测量前用白 板定标, 测量时标准光纤探头基本垂直于水面, 并且距水面上方 $1 \mathrm{~m}$, 每个点位进行 20 次的反射光谱测量, 最后取其平均值作为该点的光谱反射率, 在 $400-900 \mathrm{~nm}$ 以 $10 \mathrm{~nm}$ 为间隔取值作为研究数据. 水体透明度 的测量采用塞克盘法. 悬浮物浓度的测定是在野外采样后, 立即返回试验室对水样用 $0.45 \mu \mathrm{m}$ 的 What$\operatorname{manGF} / \mathrm{C}$ 滤纸过滤, 采用电子天平称重法测定. 本次研究共计 34 个采样点, 其中随机选取 23 个采样点数 据用来建模,剩下的 11 个样点用以模型验证.

\section{2 建模与分析}

同步采样实验分析结果显示, 石头口门水库悬浮物浓 度变化较大 $(5-81 \mathrm{mg} / \mathrm{L})$, 平均值为 $24.85 \mathrm{mg} / \mathrm{L}$; 透明度变 化范围也较大 $(0.17-1.1 \mathrm{~m})$, 平均值 $0.62 \mathrm{~m}$; 叶绿素 a 浓 度变化范围 $1.98-23.26 \mu \mathrm{g} / \mathrm{L}$, 平均值 $12.21 \mu \mathrm{g} / \mathrm{L}$. 表明该 水库悬浮泥沙含量较高, 透明度偏低, 但藻类污染还不是特 别严重.

\section{1 水体光谱分析}

为了消除因天气状况、水面波浪等外界条件造成的影 响, 对光谱数据做归一化处理, 将 $400-900 \mathrm{~nm}$ 各波段反射 率值减去 $900 \mathrm{~nm}$ 处反射率值再加上 0.0015 , 得到石头口门

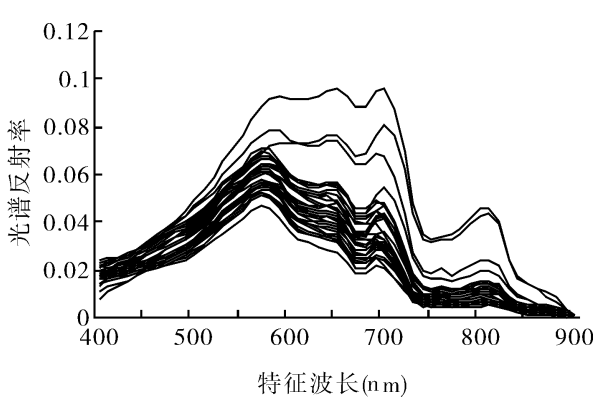

图 2 石头口门水库光谱反射率

Fig. 2 Spectral reflectance curves of

Shitoukoumen Reservoir 水库水体反射率曲线. 如图 2 所示, 其光谱反射率呈现典型的内陆水体光谱特征. 其中 $400-500 \mathrm{~nm}$ 处的 低吸收、680 nm 附近的吸收谷和 $680-710 \mathrm{~nm}$ 间的反射峰均是叶绿素的光谱特征区间. 从理论上讲,水体 的光谱特征,包含了水中向上的散射光 (水中光), 它是透射的人水光与水中悬浮物质相互作用的结果, 与 水中的悬浮泥沙含量直接相关, 因此水体光谱反射率受悬浮物含量变化的影响很大 ${ }^{[14]}$. 对于石头口门水 库, 550-600 nm 之间是悬浮泥沙的辐射峰值, 并且随着悬浮物含量的增加, 该峰值将向长波方向移动. Gitelson 等的研究表明 $700-900 \mathrm{~nm}$ 波段范围反射率对悬浮物浓度变化敏感, 可用以遥感估算悬浮物浓 度 ${ }^{[15]}$. 这是由于在近红外波段, 水体强吸收, 反射率迅速降低, 其大小主要依赖于有机和无机悬浮物质的 浓度, 对藻类色素的反应最不敏感 ${ }^{[16]}$. 虽然悬浮物的光谱特征不像叶绿素那样明显,但其散射作用使水体 的反射率在全部可见光和近红外波段都有所增大 ${ }^{[2]}$.

\section{2 悬浮物含量的高光谱定量提取}

各特征波长反射率与悬浮物的相关系数如图 3 所示, 悬浮物含量与光谱反射率普遍呈正相关, 这是由 于随着水中悬浮泥沙浓度的增加,水体在整个可见光谱段的反射亮度就会增加 ${ }^{[14]}$. $600-840 \mathrm{~nm}$ 波段相关 系数的绝对值均为 0.6 以上, 其中 $710 \mathrm{~nm}$ 处的相关性最大, 相关系数为 0.75 , 可以考虑用该波段建模来估 算透明度. 但吕恒 ${ }^{[17]}$ 等人的研究表明对光谱一阶微分将提高悬浮物估测模型的精度. 光谱微分技术是处 理高光谱遥感数据的一种重要方法, 它是对反射光谱进行数学模拟和计算不同阶数的微分差以迅速确定光 谱弯曲点及最大最小反射率的波长位置. 一般认为, 对光谱的一阶微分处理可以去除部分线性或接近线性 的背景噪声光谱对目标光谱的影响, 其中目标光谱必须是非线性的 ${ }^{[18]}$. 高光谱仪采集的是离散型数据, 光 谱数据的一阶微分可以用以下公式近似计算:

$$
R\left(\lambda_{i}\right)^{\prime}=\frac{R\left(\lambda_{i+1}\right)-R\left(\lambda_{i-1}\right)}{\lambda_{i+1}-\lambda_{i-1}}
$$

其中, $\lambda_{i+1}, \lambda_{i}, \lambda_{i-1}$ 为相邻波长; $R\left(\lambda_{i}\right)^{\prime}$ 为波长 $\lambda_{i}$ 的一阶微分反射光谱. 由公式(1) 计算的一阶微分光谱值 如图 4, 并计算各波段微分值与悬浮物含量间的相关系数, 由图 5 可知, $590 \mathrm{~nm}$ 处的相关系数绝对值最大, 
为 0.87 , 这是由于 $580-680 \mathrm{~nm}$ 对不同泥沙浓度出现辐射峰值, 对水中泥沙反映最敏感 ${ }^{[14]}$, 而对于石头口 门水库, 550-600 nm 之间是悬浮泥沙的辐射峰值, 因此以 $590 \mathrm{~nm}$ 处的一阶微分值为自变量, 悬浮物含量为 因变量建立估测模型决定系数最高 (图 6):

$$
y=92163 x+63.722\left(R^{2}=0.757, n=23, P<0.01\right)
$$

式中: $y$ 为悬浮物浓度 $(\mathrm{mg} / \mathrm{L}) ; x$ 为 $590 \mathrm{~nm}$ 处的一阶微分值. 模型的均方根误差 (RMSE) 为 $9.09 \mathrm{mg} / \mathrm{L}$, 小 于建模样本悬浮物浓度的极值差 $76 \mathrm{mg} / \mathrm{L}$, 表明用 $590 \mathrm{~nm}$ 处的一阶微分光谱值反演石头口门水库的悬浮物 含量结果较理想.

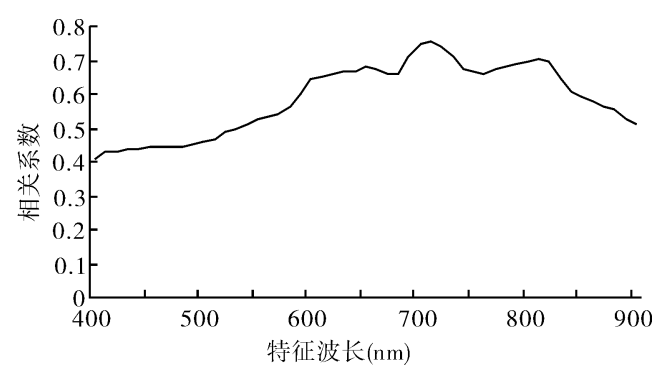

图 3 光谱反射率与悬浮物含量相关系数

Fig. 3 Correlation between TSS and spectral reflectance

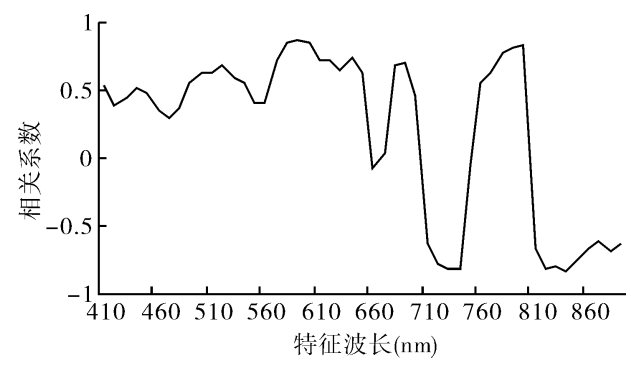

图 5 光谱一阶微分值与悬浮物含量的相关系数

Fig. 5 Correlation between TSS and first-

derivative reflectance

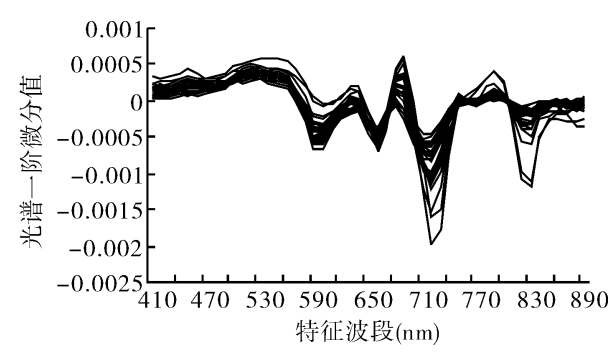

图 4 光谱反射率一阶微分

Fig. 4 First-derivative spectral reflectance

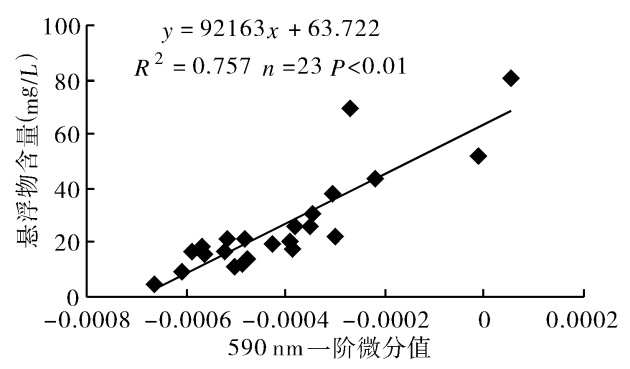

图 6 一阶微分估测模型

Fig. 6 Estimate model using first-

derivative spectral reflectance

\section{3 透明度信息的定量反演}

各特征波长反射率与透明度的相关系数如图 7 所示, 透明度与光谱反射率普遍呈负相关, 这是由于透 明度与水中物质如叶绿素 $\mathrm{a} 、$ 悬浮物等关系密切, 水中物质含量越少, 水体透明度越大, 光谱反射率就越 低 ${ }^{[19]}$. 根据张运林等人在研究浅水湖泊水体过程中, 发现湖泊水体透明度主要受悬浮物含量和组成影 响 ${ }^{[20]}$, 这其中包括悬浮物的矿物组成、粒度组成等. 对于石头口门水库而言, 上游严重的水土流失带来大 量泥沙, 使得水体悬浮物含量较大, 并且其矿物组成、粒度组成相对比较均匀, 导致透明度受悬浮物含量影 响较大, 受叶绿素 $\mathrm{a}$ 浓度等其他物质的影响较小. 透明度与悬浮物含量和叶绿素 $\mathrm{a}$ 浓度的相关系数分别为 -0.80 和 -0.12 . 从相关系数可以看出, 透明度与悬浮物含量存在明显的负相关. 这是由于随着水中悬浮 物质含量 (混浊度) 的增加, 反射率明显增强, 衰减系数增大, 光对水的穿深能力减弱, 透明度也就明显下 降 ${ }^{[14]}$. 因此可以利用悬浮物含量反演水体透明度信息. 经计算, 通过对透明度值进行对数转换, 将有助于 其定量遥感(图 8)：

$$
y=-0.0229 x+0.0061\left(R^{2}=0.7877, n=23, P<0.01\right)
$$

式中: $y$ 为 $\ln (S D D)$; $x$ 为悬浮物浓度 $(\mathrm{mg} / \mathrm{L})$. 该模型的决定系数较高, 均方根误差为 $0.12 \mathrm{~m}$, 小于建模样本 
透明度的极值差 $0.8 \mathrm{~m}$.

\section{4 模型验证}

为了分析模型的适用性以及由模型模拟造成的误差,选用剩下的 11 个样本数据对上述模型进行验证. 先利用公式 (2) 计算检验样本的悬浮物含量, 估测值与实测值的对比结果见图 9 , 验证模型的决定系数 $R^{2}$ 为 0.79 , 均方根误差为 $7.15 \mathrm{mg} / \mathrm{L}$, 小于检验样本悬浮物含量的极值差 $43 \mathrm{mg} / \mathrm{L}$. 而利用悬浮物含量反演透明 度的验证模型决定系数 $R^{2}$ 和 $R M S E$ 分别为 $0.82 、 0.11 \mathrm{~m}$ (图 10 ), 小于检验样本透明度极值差 $0.73 \mathrm{~m}$. 总体 而言,验证结果均较理想,可用上述方法估测石头口门水库悬浮物含量和透明度信息.

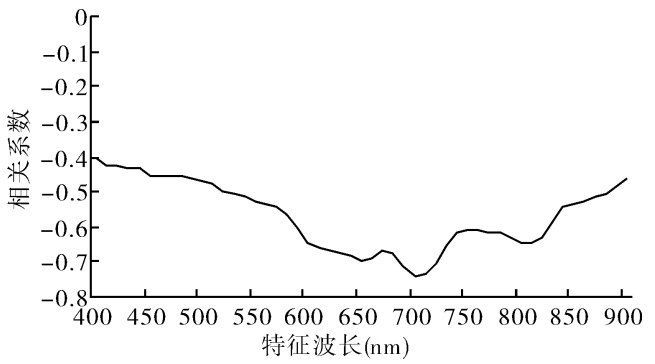

图 7 光谱反射率与透明度相关系数

Fig. 7 Correlation between $S D D$ and spectral reflectance

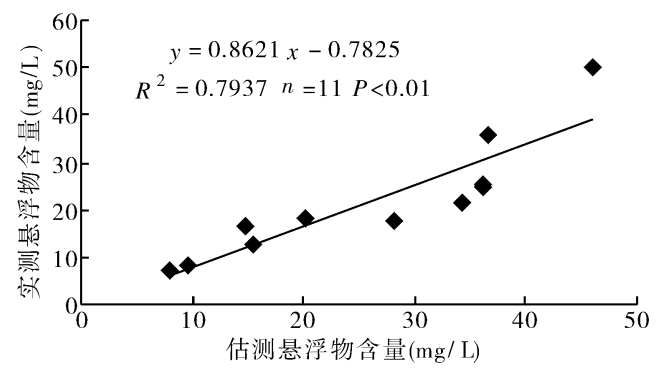

图 9 悬浮物含量反演模型的验证

Fig. 9 Test of the TSS model

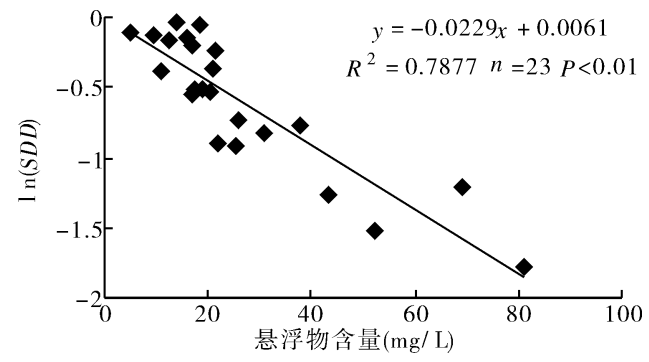

图 8 透明度含量估测模型

Fig. 8 Estimate model of $S D D$

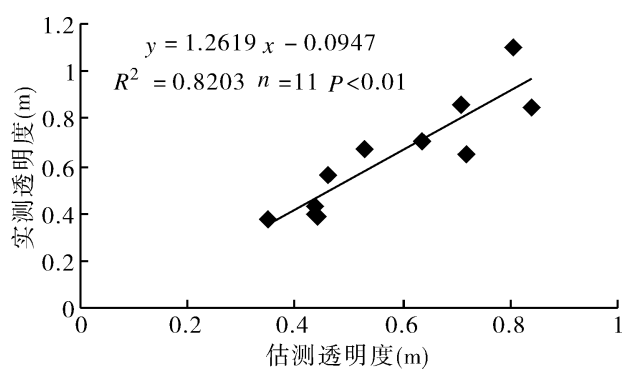

图 10 利用悬浮物反演透明度模型的验证

Fig. 10 Test of the SDD model using TSS

\section{3 结论}

通过光谱分析,得知长春市石头口门水库水体光谱反射率呈现典型的内陆水体光谱特征,550-600 nm 之间是其悬浮泥沙的辐射峰值. 经分析计算, $590 \mathrm{~nm}$ 处的一阶微分值与悬浮物含量的相关系数最高 $(r=$ 0.87 ), 用其建立的悬浮物估测模型决定系数 $R^{2}$ 和均方根误差 $(R M S E)$ 分别为 $0.76 、 9.09 \mathrm{mg} / \mathrm{L}$. 由于上游 严重的水土流失带来大量的悬浮泥沙,使得水体透明度主要受悬浮物含量的影响,两者存在较强的相关性 $(r=-0.80)$, 因此可通过悬浮物含量信息反演透明度信息, 建立的估测模型的 $R^{2}$ 和均方根误差分别为 0.79 和 $0.12 \mathrm{~m}$. 对上述模型的验证结果表明,对于石头口门水库而言,用该方法能较好的估测水体悬浮物 含量和透明度. 以上模型都呈极显著水平 $P<0.01$.

虽然本研究可为今后大面积反演石头口门水库悬浮物含量信息奠定基础,并为多途径提取透明度信息 提供一种思路,但限于样点的区域性和采样时间季节,模型通用性不强, 同时为提高模型估算精度和普适 性, 必须增加对悬浮物、浮游植物和黄色物质内在光学特征及悬浮物的矿物组成、粒度组成等的测量和研 究,这需要在今后的工作中继续深人研究. 


\section{4 参考文献}

[1] 周 艺, 周伟奇, 王世新等. 遥感技术在内陆水体水质监测中的应用. 水科学进展, 2004, 15(3): $312-317$.

[2] 疏小舟, 尹 球, 匡定波. 内陆水体藻类叶绿素浓度与反射光谱特征的关系. 遥感学报, 2000,4 (1) $: 41-45$.

[3] 韩 震, 陈西庆, 恽才兴. 海洋高广谱遥感研究进展. 海洋科学, 2003, 27(1):22-25.

[4] 张运林, 秦伯强, 陈伟民等. 太湖水体中悬浮物研究. 长江流域资源与环境, 2004, 13 (3): 266 -271 .

[5] 汪小钦, 王钦敏, 邬群勇等. 遥感在悬浮物质浓度提取中的应用一以福建闽江口为例. 遥感学报, 2003,7 ( 1 ) :54 - 57 .

[6] Mishra A K. Retrieval of suspended sediment concentration in the estuarine waters using IRS-1C WiFS data. International Journal of Applied Earth Observation and Geoinformation, 2004, 6:83 - 95.

[7] 刘堂友, 匡定波, 尹 球. 湖泊藻类叶绿素 $\mathrm{a}$ 和悬浮物浓度的高光谱定量遥感模型研究. 红外与毫 米波学报, 2004, 23(1): $11-15$.

[8] Richard L Miller, Brent A McKee. Using MODIS Terra $250 \mathrm{~m}$ imagery to map concentrations of total suspended matter in coastal waters. Remote Sensing of Environment, 2004, 93:259-266.

[9] 马荣华, 戴锦芳. 结合 Landsat ETM 与实测光谱估测太湖叶绿素及县浮物含量. 湖泊科学, 2005,17 (2) :97-103.

[10] 李云梅, 黄家柱, 陆皖宁等. 基于分析模型的太湖悬浮物浓度遥感监测. 海洋与湖沼, 2006, 37(2): $171-176$.

[11] 吕跃明. 浅谈地表水透明度监测结果与现场光线的关系. 四川环境, 2003, 22(6):35, 38.

[12] 平仲良. 用实测海水透明度数据和 NOAA 卫星数据计算黄海悬浮体含量. 海洋与湖沼, 1993, 24 (1) $: 24-30$.

[13] 肖桂义, 陆继龙, 蔡 波等. 长春市石头口门水库水质演变及对策. 地质与勘探, 2003, 39(6):61 -63 .

[14] 赵英时. 遥感应用分析原理与方法. 北京: 科学出版社, 2003:419-421.

[15] Gitelson A A, Garbuzov G, Szilagyi et al. Quantative remote sensing methods for real-time monitoring of inland waters quality. Int J Remote Sensing, 1993, 14(7):1269 - 1295.

[16] Han L, Rundquist D C, Liu L L et al. The spectral responses of algal chlorophyll in water with varying levels of suspended sediment. International Journal of Remote Sensing, 1994, 15: 3707 - 3718.

[17] 吕 恒,李新国, 江 南. 基于反射光谱和模拟 MERIS 数据的太湖悬浮物遥感定量模型. 湖泊科学, $2005, \mathbf{1 7}(2): 104-109$.

[18] 浦瑞良, 宫 鹏. 高光谱遥感及其应用. 北京: 高等教育出版社, 2000:53.

[19] 段洪涛, 张 柏, 宋开山等. 长春南湖水体透明度高光谱定量模型研究. 中国科学院研究生院学报, 2006, $23(5)$ : 634 - 639.

[20] 张运林, 秦伯强, 陈伟民等. 太湖水体透明度的分析、变化及相关分析. 海洋湖沼通报, 2003, (2): $30-36$. 